\title{
Naked Plasmid DNA Formulation: Effect of Different Disaccharides on Stability after Lyophilisation
}

\author{
Susanne G. L. Quaak, ${ }^{1,4}$ John B. A. G. Haanen, ${ }^{2}$ Jos H. Beijnen, ${ }^{1,3}$ and Bastiaan Nuijen ${ }^{1}$
}

\begin{abstract}
Received 15 October 2009; accepted 1 February 2010; published online 4 March 2010
Abstract. Since plasmid DNA (pDNA) is unstable in solution, lyophilisation can be used to increase product shelf life. To prevent stress on pDNA molecules during lyophilisation, cryo- and lyoprotectants have to be added to the formulation. This study assessed the effect of disaccharides on naked pDNA stability after lyophilisation using accelerated stability studies. Naked pDNA was lyophilised with sucrose, trehalose, maltose or lactose in an excipient/DNA $w / w$ ratio of 20 . To one part of the vials extra residual moisture was introduced by placing the vials half opened in a $25^{\circ} \mathrm{C} / 60 \% \mathrm{RH}$ climate chamber, before placing all vials in climate chambers $\left(25^{\circ} \mathrm{C} / 60 \% \mathrm{RH}\right.$ and $\left.40^{\circ} \mathrm{C} / 75 \% \mathrm{RH}\right)$ for stability studies. An ex vivo human skin model was used to assess the effect of disaccharides on transfection efficiency. Lyophilisation resulted in amorphous cakes for all disaccharides with a residual water content of $0.8 \% w / w$. Storage at $40^{\circ} \mathrm{C} / 75 \% \mathrm{RH}$ resulted in decreasing supercoiled (SC) purity levels (sucrose and trehalose maintained approximately $80 \%$ SC purity), but not in physical collapse. The addition of residual moisture (values between $7.5 \%$ and $10 \% \mathrm{w} / \mathrm{w}$ ) resulted in rapid collapse except for trehalose and decreasing SC purity for all formulations. In a separate experiment disaccharide formulation solutions show a slight but significant reduction ( $<3 \%$ with sucrose and maltose) in transfection efficiency when compared to pDNA dissolved in water. We demonstrate that disaccharides, like sucrose and trehalose, are effective lyoprotectants for naked pDNA.
\end{abstract}

KEY WORDS: disaccharides; formulation; lyophilisation; naked pDNA; stability.

\section{INTRODUCTION}

Gene therapy using plasmid DNA (pDNA) for vaccination against cancer requires DNA-based pharmaceuticals which can be stored, shipped and applied even under critical environmental conditions. The physical and chemical stability of pDNA is influenced by the formulation (e.g., excipients, dosage form) and storage conditions (1-3). During storage of the supercoiled (SC) pDNA, the topoisoform associated with the highest transfection efficiency, is mainly converted to open circular (OC) pDNA (single strand breaks) and linear pDNA (double stranded break; 3). The SC topology (and transfection efficiency) can be maintained when pDNA solutions are stored at $-80^{\circ} \mathrm{C}$ (3). However, for clinical practise it is desirable that the product can be stored at higher temperatures, especially when shipping for instance to developing countries. Depending on the excipients in the liquid formulation, solutions can be stable for up to 12 months when stored at $4^{\circ} \mathrm{C}(2,3)$ and for at

\footnotetext{
${ }^{1}$ Department of Pharmacy and Pharmacology, Slotervaart Hospital/ The Netherlands Cancer Institute, Louwesweg 6, 1066 EC, Amsterdam, The Netherlands.

${ }^{2}$ Division of Immunology, The Netherlands Cancer Institute, Amsterdam, The Netherlands.

${ }^{3}$ Department of Biomedical Analysis, Section of Drug Toxicology, Utrecht University, Utrecht, The Netherlands.

${ }^{4}$ To whom correspondence should be addressed. (e-mail: Susanne. Quaak@slz.nl)
}

least 3 years when stored at $-20^{\circ} \mathrm{C}$ (2). To prolong the shelf life of pDNA formulations at higher temperatures, lyophilisation can be used. An additional advantage of lyophilisation is that it is possible to concentrate solutions by reconstitution of the dried product with a smaller volume (4). Lyophilisation may increase the stability of pDNA under long-term storage, but may also cause some damage during the subsequent freezing and drying steps of the lyophilisation process (5-7). Lyophilisation causes the removal of the hydration sphere around a molecule (5). It has been reported with X-ray diffraction, infrared and ultraviolet spectroscopy that hydration water is necessary for maintaining the structural integrity of the DNA molecule. In the absence of water, the ordered conformation is lost and base stacking is destroyed (8). Lyophilisation without protecting agent results in significant loss of plasmid DNA activity (up to $75 \%$ ), due to loss of hydration water and subsequent changes in conformation $(4,5)$. Agents that can substitute for non-freezable water, such as sugars, can demonstrate cryo- and lyoprotective properties for DNA and other molecules during lyophilisation $(5,9)$. In the pDNA field extensive research on the stabilisation of non-viral DNA vectors, i.e., pDNA complexed with lipids or polymers, has been conducted (4,9-14). In this respect, different types of sugars have been evaluated for their cryo- and lyoprotective properties. Disaccharides and oligosaccharides like dextrans or inulins or combinations of both have proven most efficient $(4,7,9-12,15-17)$. Focus of these studies, however, was primarily the physical stabilisation of the non-viral pDNA vector particles 
with respect to for instance size and zeta potential. To the best of our knowledge few if any studies have been conducted on the stabilising effect of disaccharides on naked pDNA upon lyophilisation and storage under various conditions. Disaccharides, like sucrose, trehalose, maltose and lactose have proven excellent stabilisers for proteins since they are able to form hydrogen bonds $(18,19)$ also sucrose has been shown to work via preferential exclusion, therefore favouring the shape with the smallest surface area (20). Possibly these hydroxyl groups could also stabilise pDNA, since pDNA is also able to form hydrogen bonds. In fact, it has been shown that hydrogen bonding excipients are effective against moisture-induced aggregation of DNA in a solid state (21). In this study, we assessed the protective properties of different disaccharides on naked DNA by means of accelerated stability studies using elevated temperatures and increased residual moisture content. The interaction of water vapour with crystalline and amorphous solids can play an important role in the physical form and the potential for physical transformation such as cake softening or collapse. The sorption of water vapour depends on the affinity of the material for water, the physical state of the solid, relative humidity, temperature and time (22). As template, we used the novel in-house developed plasmid DNA vaccine encoding recombinant MART-1 and tetanus toxin fragment-c (pDERMATT). pDERMATT is currently in a phase I clinical study in advanced stage melanoma patients investigating its toxicity upon administration by intradermal tattooing and its efficacy in inducing a specific $\mathrm{T}$ cell immune response. Besides stability, the influence of different disaccharides on the transfection efficiency of pDNA was determined.

\section{MATERIALS AND METHODS}

\section{Chemicals}

The insert of the pVAX-based plasmid pDERMATT (Fig. 1; $3.8 \mathrm{~kb}$ ) was designed at The Netherlands Cancer Institute (NKI-AvL, Amsterdam, The Netherlands). pDERMATT and the reporter plasmid pVAX:Luc (4.7 kb) were produced in-house (AmBTU, Amsterdam, The Netherlands; 23). Sucrose and lactose (Ph. Eur. Grade) were purchased from BUFA (Uitgeest, The Netherlands). Trehalose, maltose (both highly pure $\geq 99.0 \%$ ), Tris, $\mathrm{NaCl}$ and water for chromatography were obtained from Merck (Darmstadt, Germany). Sterile water for injections was purchased from B. Braun (Melsungen, Germany). Isopropanol and 25\% (w/v) $\mathrm{HCl}$ were obtained from Biosolve B.V. (Amsterdam, The

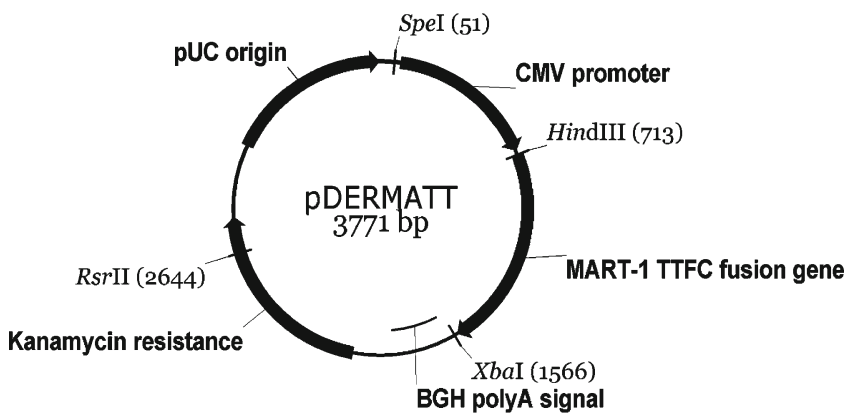

Fig. 1. Plasmid DNA map of pDERMATT (plasmid DNA encoding recombinant MART-1 and tetanus toxin fragment-c) including selected restriction sites
Netherlands). All chemicals obtained were of analytical grade and used without further purification.

\section{High Pressure Liquid Chromatography}

pDERMATT purity was determined using a validated anion-exchange (AEX)-high pressure liquid chromatography (HPLC) system, with a TSKgel DNA-NPR column ( $75 \mathrm{~mm} \times 4.6 \mathrm{~mm}$ I.D. particle size $2.5 \mu \mathrm{m}$, Anachem House, Luton, England) and linear $\mathrm{NaCl}$ gradient from $0.45-0.53 \mathrm{M}$ (A: $20 \mathrm{mM}$ tris, pH9.0 in 10\% IPA; B: $20 \mathrm{mM}$ tris, $1 \mathrm{M} \mathrm{NaCl}$, pH9.0 in $10 \%$ IPA), as described previously (24).

\section{Pharmaceutical Formulation Development}

\section{Differential Scanning Calorimetry}

Glass transition temperatures (Tg) of pDERMATT formulations were determined using a Q2000 DSC equipped with a refrigerated cooling accessory for low temperature in the T4P mode (TA Instruments, New Castle, DE, USA). Temperature scale and heat flow were calibrated with indium. Approximately $5 \mathrm{mg}$ of lyophilised product was transferred into Tzero Aluminium pans, hermetically closed, equilibrated at $-40^{\circ} \mathrm{C}$ and heated to $70^{\circ} \mathrm{C}$ or $120^{\circ} \mathrm{C}$ with $2^{\circ} \mathrm{C} / \mathrm{min}$ and $1^{\circ} \mathrm{C} / \mathrm{min}$ modulation for partly wet or fully dried formulations, respectively. An empty pan was used as reference.

\section{Manufacture and Stability}

Formulation solutions with four disaccharides (sucrose, trehalose, maltose or lactose) were prepared. Each formulation solution contained $1 \mathrm{mg} / \mathrm{ml}$ pDERMATT and $20 \mathrm{mg} / \mathrm{ml}$ disaccharide (corresponding to an excipient/DNA ratio of $20 w / w)$. Reconstitution with five times smaller volume gives an isotonic sucrose solution containing $5 \mathrm{mg} / \mathrm{ml}$ pDERMATT (concentration requested for the phase I clinical trial). Aliquots of $2 \mathrm{ml}$ were filled into $8 \mathrm{ml}$ colourless glass vials (hydrolytic class type 1 Fiolax clear, Münnerstadter Glaswarenfabrik, Münnerstadt, Germany). The vials were partly closed with grey butyl rubber lyophilisation closures (Type FM157/1, Helvoet Pharma N.V., Alken, Belgium) and loaded into the freeze dryer (Model Lyovac GT4, GEA Lyophil GmbH, Hürth, Germany). Vials were frozen to $-35^{\circ} \mathrm{C}$ in $2 \mathrm{~h}$. Primary drying $(50 \mathrm{~h})$ was started at a shelf temperature of $-35^{\circ} \mathrm{C}$ and a chamber pressure of 0.4 mbar. During the primary drying phase temperature was elevated to $-12^{\circ} \mathrm{C}$ (after $1 \mathrm{~h}$ the temperature is linearly increased to $-25^{\circ} \mathrm{C}$ in $6 \mathrm{~h}$, this temperature was maintained for $38 \mathrm{~h}$ after which the temperature is linearly increased to $-12^{\circ} \mathrm{C}$ in $5 \mathrm{~h}$ ). Secondary drying $(10 \mathrm{~h})$ was carried out at a shelf temperature of $25^{\circ} \mathrm{C}$ and a chamber pressure of 0.2 mbar. All vials were closed pneumatically under vacuum. Half the amount of vials (the fully dried (FD) formulations) were directly capped with flip-off caps (West Pharmaceutical, Germany) and placed into $25^{\circ} \mathrm{C} / 60 \% \mathrm{RH}$ and $40^{\circ} \mathrm{C} / 75 \% \mathrm{RH}$ climate chambers (HEKK 0057, Weiss Technik ltd., Buckinghamshire, UK). The remainder of the vials were weighed, opened and placed into the $25^{\circ} \mathrm{C} / 60 \% \mathrm{RH}$ climate chamber. After $1 \mathrm{~h}$ of incubation the vials were removed, closed, capped with flip-off caps and placed into the climate chambers for the accelerated stability study (the 
partly wet (PW) formulations). FD and PW samples were analyzed after 1, 3 and 6 months of storage with HPLC and AGE analysis to determine the stability of the freeze-dried finished product.

\section{Residual Water Determination}

The residual water content was determined using a standard Karl Fischer titration. The cake was dissolved in water free methanol and transferred into the reaction vessel $(N=3)$.

\section{Transfection Efficiency}

\section{Tattooing of Ex Vivo Human Skin}

Healthy human abdominal skin from female patients was obtained from the plastic surgery department, according to institutional guidelines. Subcutaneous fat was directly removed by blunt dissection. pVAX:Luc disaccharide solutions were administered into the intact skin, within $2 \mathrm{~h}$ after surgical removal, by DNA tattooing to allow longitudinal luciferase expression measurements. This skin model was described before for the optimization of tattooing of naked DNA in skin (25). In brief, $10 \mu 1$ of the formulation was applied onto the skin into a custom fabricated mould to keep the area of tattooing constant (diameter $8 \mathrm{~mm}$, surface $50 \mathrm{~mm}^{2}$ ). The droplet of formulation was subsequently administered into skin using a PMU® tattoo machine (MT Derm GmbH, Berlin, Germany). For all tattoos, 9-needle cartridges at an oscillating frequency of $100 \mathrm{~Hz}$ were used. The needle depth was adjusted to $1.5 \mathrm{~mm}$ and tattoo duration was $20 \mathrm{~s}$. After tattooing, skin samples were kept at $5 \% \mathrm{CO}_{2}, 37^{\circ} \mathrm{C}$ in complete keratinocyte serumfree medium containing $1 \%$ penicillin/streptomycin and $0.25 \mu \mathrm{g} / \mathrm{ml}$ amphotericin B (all Invitrogen). During this incubation, skin was cultured at the air-medium interface with the epidermis exposed to the air to mimic the natural situation.

\section{Longitudinal Measurement of Antigen Expression in Human Skin}

The expression of luciferase was measured in intact skin samples at 3, 18, 24 and $48 \mathrm{~h}$ after tattooing. The substrate luciferin (Xenogen, Hopkinton, MA,USA) was added to the medium in a final concentration of $45 \mu \mathrm{g} / \mathrm{ml}$. After the addition of the substrate $(30 \mathrm{~min})$, luminescence produced by active luciferase was acquired during $30 \mathrm{~s}$ with an IVIS system 100 CCD camera (Xenogen, Hopkinton, MA, USA). Signal intensity was quantified as the sum of all detected light within the tattoo area of interest. During each measurement, background luminescence was measured to allow correction during data analysis. After each measurement, medium was refreshed to remove residual luciferin.

\section{Linear Mixed Effect Model}

To study the effect of different disaccharides on the level of antigen (i.e., luciferase) expression, the natural log transform of the area under the curve (AUC) over the 48-h period was analyzed. To account for possible within skin correlation of the repeated measurements of antigen expression, a linear mixed effects model was constructed. The fixed effect was the solution type. Patient identifier was implemented as the random grouping variable. Pair-wise interactions were examined between all fixed effects. The significance level was set at 0.05. Conventional residual analysis was performed to assess model fit. Data analysis was performed with Splus v6.2 pro (Insightful, Seattle, WA, USA).

\section{RESULTS}

In this study, we used a pDNA formulation at a concentration of $1 \mathrm{mg} / \mathrm{ml}$ to which $20 \mathrm{mg} / \mathrm{ml}$ of disaccharide was added. After lyophilisation, this composition enables reconstitution of the dried product to an isotonic solution with a final concentration of $5 \mathrm{mg} / \mathrm{ml} \mathrm{pDNA}$ for intradermal (ID) administration. The resulting disaccharide/DNA $w / w$ ratio of 20 in the formulation solution is much lower than ratios reported in literature concerning pDNA stabilisation upon lyophilisation, which range from 100 to 4,000 (4,7). It was found that the levels of disaccharides needed for stability result in hypertonic solutions upon rehydration that are not compatible with parenteral (e.g., SC, IM, ID) injection. These studies, however, focused on non-viral pDNA carriers instead of naked pDNA for which stabilisation and prevention of aggregation of particles is of additional importance. Another major difference in our study is the significantly higher DNA starting concentration (e.g., $1 \mathrm{mg} / \mathrm{ml}$ vs $20 \mu \mathrm{g} / \mathrm{ml}$ (4)).

\section{Formulation Glass Transitions}

The disaccharide formulation solutions gave a $\mathrm{Tg}^{\prime}$ between $-32^{\circ} \mathrm{C}$ and $-34^{\circ} \mathrm{C}$, which is comparable to literature (26-29). Furthermore the presence of pDNA had very little influence on the $\mathrm{Tg}^{\prime}$ (data not shown). This finding is in contrast to data shown by Jameel et al., where oligonucleotides increase the $\mathrm{Tg}^{\prime}$ of lactose (30). Consequently, we lyophilised all formulations using the same lyophilisation cycle, resulting in a residual water content of approximately $0.8 \%(w / w)$ for the FD formulations (Table I). The Tg values show slightly lower values compared to data reported in literature (31). This is likely due to the slightly higher residual moisture content of the pDNA formulations. Additionally, pDNA itself possibly affects Tg temperatures as well, since the $\mathrm{Tg}$ values of multi-component systems show large variations as reported earlier for protein formulations (31).

Table I. Tg and Moisture Content of Freeze-dried pDERMATT Formulations

\begin{tabular}{lcc}
\hline Formulation & Tg of formulation $\left({ }^{\circ} \mathrm{C}\right)$ & $\begin{array}{l}\text { Moisture content } \\
(\%, w / w)\end{array}$ \\
\hline $\begin{array}{l}\text { Fully dried } \\
\text { Trehalose }\end{array}$ & 80.5 & $0.8( \pm 0.04)$ \\
Lactose & 67.6 & $0.8( \pm 0.05)$ \\
Maltose & 66.1 & $0.8( \pm 0.07)$ \\
Sucrose & 45.8 & $0.8( \pm 0.08)$ \\
Partly wet $(1 \mathrm{~h}$ & & \\
$\left.25^{\circ} \mathrm{C} / 60 \% \mathrm{RH}\right)$ & & $10.0( \pm 0.16)$ \\
Trehalose & 26.1 & $8.6( \pm 0.24)$ \\
Lactose & 32.6 & $7.5( \pm 0.13)$ \\
Maltose & 20.5 & $8.4( \pm 0.40)$ \\
Sucrose & 10.8 & \\
\hline
\end{tabular}




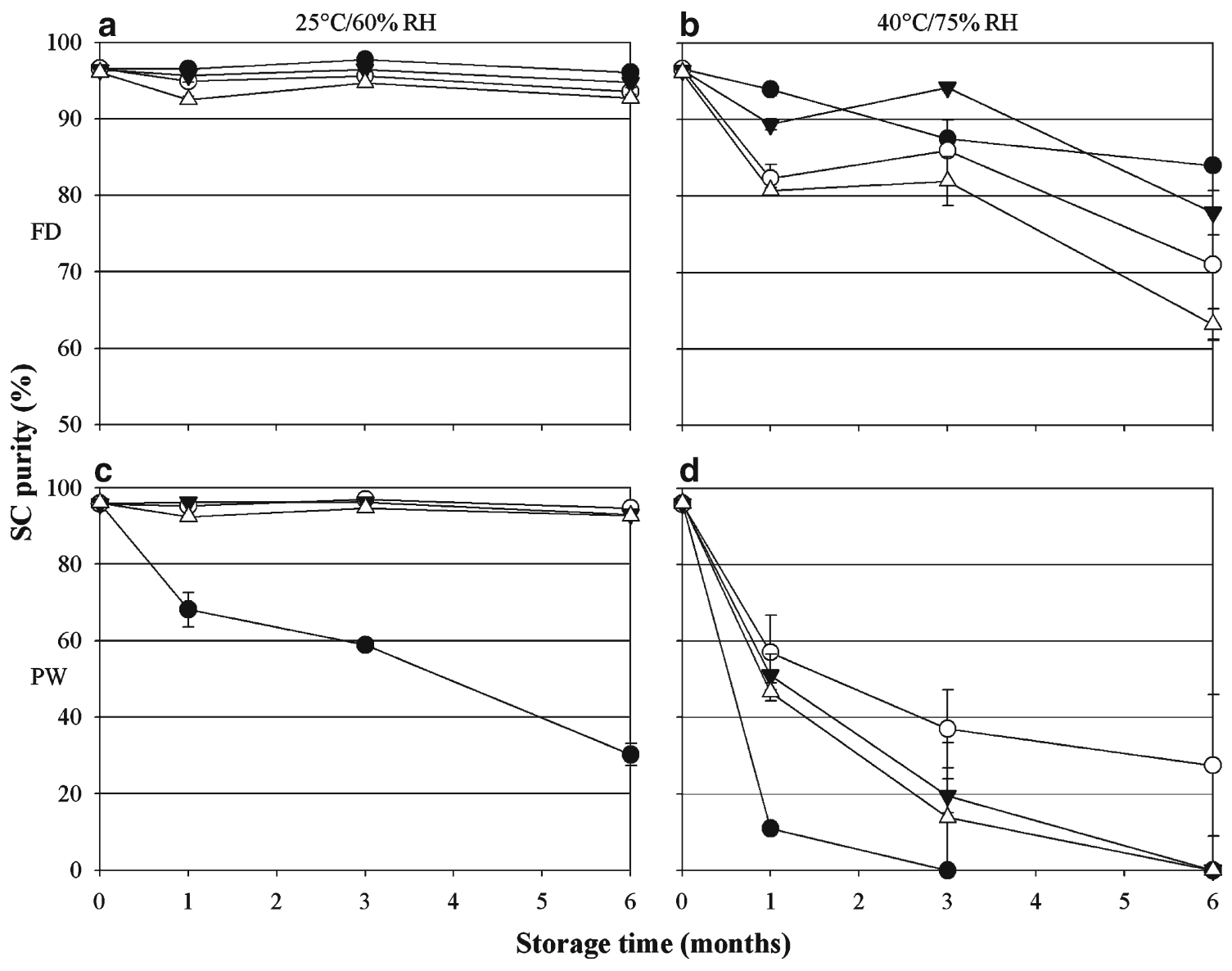

Fig. 2. Purity of pDERMATT lyophilised with four different disaccharides (filled circles represent sucrose; filled nabla represents trehalose; circles represent maltose; triangles represent lactose) fully dried (a,b) and partly wet (c,d) after storage at $25^{\circ} \mathrm{C} / 60 \% \mathrm{RH}(\mathbf{a}, \mathbf{c})$ and $40^{\circ} \mathrm{C} / 75 \% \mathrm{RH}(\mathbf{b}, \mathbf{d})$

Consistent with literature, trehalose displayed the highest $\mathrm{Tg}$, followed by lactose, maltose and sucrose. The moisture contents of the PW formulations were in the range between $7.5 \%$ and $10.0 \%(w / w)$. As expected, these moisture contents resulted in markedly lower $\mathrm{Tg}$ temperatures (Table I). Again, the trehalose, maltose and lactose formulations had a higher $\mathrm{Tg}$ than the sucrose formulation.

\section{Accelerated Stability Study of Lyophilised Formulations}

Figure 2 shows the SC purity of the FD and PW formulations after storage at the two different storage conditions. In the FD formulations all disaccharides were able to keep the SC purity well above $90 \%$ during storage for at least 6 months at $25^{\circ} \mathrm{C} / 60 \%$ RH (Fig. 2a). However, when

Table II. Visual Observation of PW pDERMATT Formulations ( 1 h $\left.25^{\circ} \mathrm{C} / 60 \% \mathrm{RH}\right)$ Stored at Various Temperatures and Relative Humidity; FD pDERMATT Formulations Stored at Both Storage Conditions Showed no Collapse for Either Disaccharide

\begin{tabular}{|c|c|c|c|c|}
\hline \multirow[b]{2}{*}{ Storage condition/formulation } & \multicolumn{4}{|c|}{ Visual observation after storage } \\
\hline & $t=0$ & $t=1$ month & $t=3$ months & $t=6$ months \\
\hline \multicolumn{5}{|l|}{$25^{\circ} \mathrm{C} / 60 \% \mathrm{RH}$} \\
\hline Trehalose & - & - & - & - \\
\hline Lactose & - & - & - & - \\
\hline Maltose & - & Partial collapse & Partial collapse & Partial collapse \\
\hline Sucrose & Partial collapse & Collapse & Collapse & Collapse \\
\hline \multicolumn{5}{|l|}{$40^{\circ} \mathrm{C} / 75 \% \mathrm{RH}$} \\
\hline Trehalose & - & - & - & Partial collapse \\
\hline Lactose & - & Collapse & Collapse & Collapse \\
\hline Maltose & - & Collapse & Collapse & Collapse \\
\hline Sucrose & Partial collapse & Collapse & Collapse & Collapse \\
\hline
\end{tabular}


the formulations are stored at $40^{\circ} \mathrm{C} / 75 \% \mathrm{RH}$ the SC purity levels significantly drop with sucrose and trehalose performing best with approximately $80 \%$ SC remaining after 6 months of storage (Fig. 2b). None of the FD formulations showed collapse at either storage condition, in contrast to the PW formulations. As expected, due to its low Tg temperature sucrose formulations readily collapsed at both storage conditions (Table II), and with this collapse SC purity dramatically decreased (Fig. 2c,d). Although the maltose formulations at $25^{\circ} \mathrm{C} / 60 \% \mathrm{RH}$ showed partial collapse SC purity was not affected. Trehalose and lactose were able to maintain the cake structure and SC purity at this storage temperature. However when the $\mathrm{PW}$ formulations are stored at $40^{\circ} \mathrm{C} / 75 \% \mathrm{RH}$, SC purity decreases rapidly in all formulations (Fig. 2d), although the trehalose formulation maintained cake structure up to 6 months of storage. Upon degradation, SC pDNA is initially mainly converted to OC pDNA as exemplified for sucrose in Fig. 3. This DNA then degrades over time in smaller oligonucleotides appearing in the flow through with HPLC analysis or as a smear in AGE analysis (data not shown).

\section{Luciferase Expression with Addition of Disaccharides}

To assess the effect of excipients on antigen expression, solutions of a reporter plasmid (pVAX:Luc) 100\% SC containing $10 \%(w / v)$ of one of the disaccharides were applied to ex vivo human skin (25). Interestingly, pDNA without any excipients gave a significantly higher antigen expression (higher AUC) than when lyoprotectants are added to the formulation (all $p$ values $<0.01$ ). Figure 4 shows the decrease in AUC for each disaccharide compared to pDNA dissolved in WfI. When comparing the disaccharides

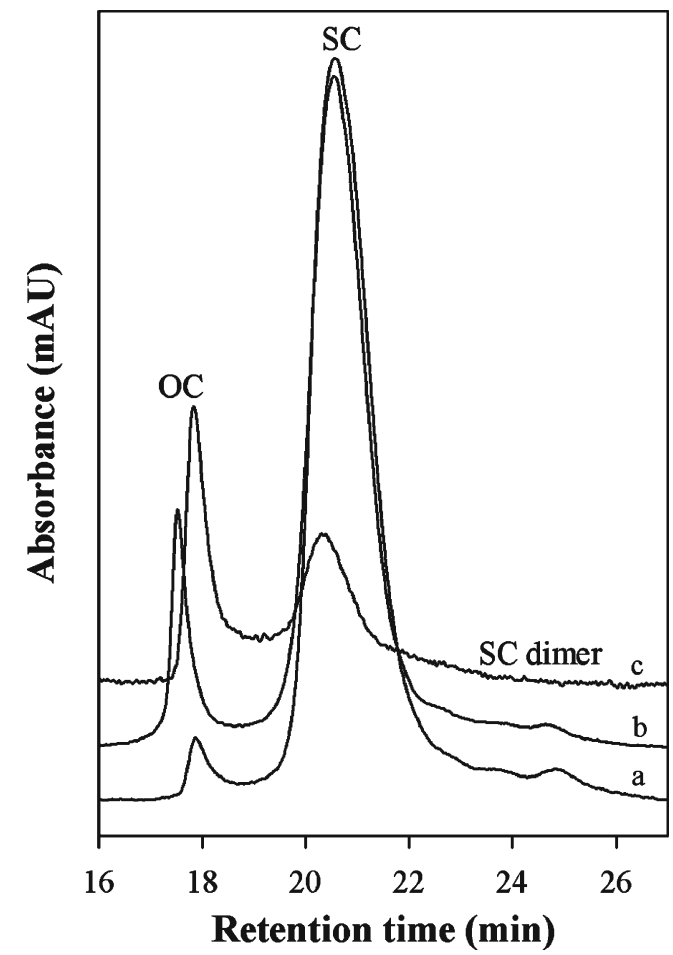

Fig. 3. Representative chromatograms of pDERMATT in sucrose (PW) during storage at $40^{\circ} \mathrm{C} / 75 \% \mathrm{RH}$; at $t=0(a), t=1$ month $(b)$ and $t=6$ months $(c) .1 \mu \mathrm{g}$ injection, detection at $260 \mathrm{~nm}$

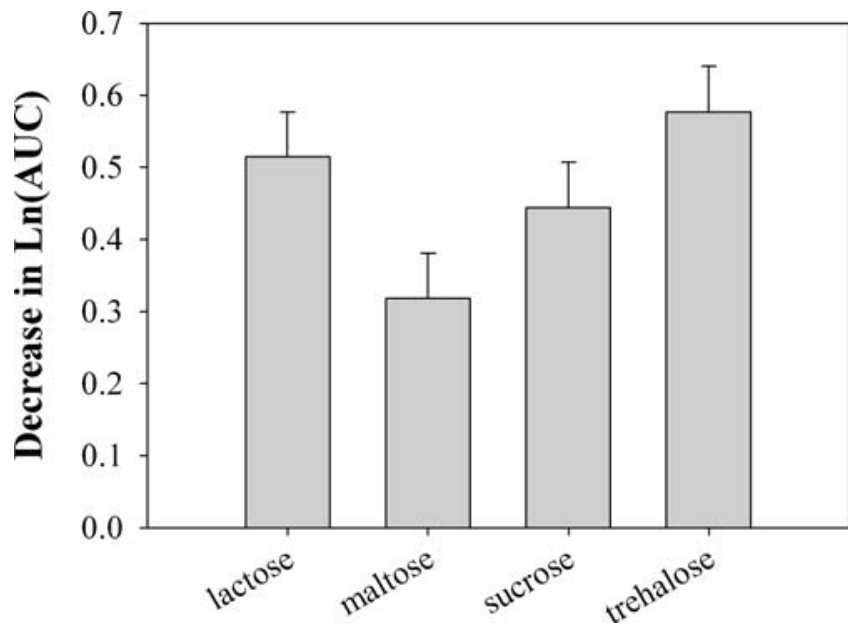

Fig. 4. Decrease in Ln(AUC) of luciferase expression (photons/s) in human ex vivo skin after tattoo administration $(2 \mathrm{mg} / \mathrm{ml} \mathrm{pVAX}: \mathrm{Luc}$, needle depth $1.5 \mathrm{~mm}, 100 \mathrm{~Hz}, 20 \mathrm{~s}$ ) when formulated in disaccharides $v s$ dissolved in water. pDNA dissolved in water without any excipients gave a significant better expression $(\operatorname{Ln}(\mathrm{AUC})=15.6)$ than when disaccharides are added to the formulation (all $p$ values $<0.01$ ). Of the tested disaccharides only maltose gave a significant better expression than trehalose ( $p$ value 0.001 ) and lactose ( $p$ value 0.01 ). Maltose compared to sucrose gave a $p$ value of 0.104

amongst each other, maltose performed significantly better than trehalose $(p=0.001)$ or lactose $(p=0.01)$. Between sucrose and the other disaccharides there were no significant differences in performance. A decrease in SC purity to $75 \%$ showed that expression is related to the SC purity rather than the disaccharide that was used in the formulation solution (data not shown).

\section{DISCUSSION AND CONCLUSION}

This accelerated stability study shows that the pDNA vaccine pDERMATT can be efficiently protected using disaccharides in a ratio of $20 \mathrm{w} / \mathrm{w}$. At a storage condition of $25^{\circ} \mathrm{C} / 60 \% \mathrm{RH}$ no degradation of pDERMATT could be observed for at least 6 months of storage, irrespective of the disaccharide used. Even for the PW formulations, simulating the increase in moisture content of lyophilised formulations upon storage, no decrease in SC content could be observed with the exception of the sucrose-based formulation. It may be argued, however, that the induced moisture levels of $7.5-10 \%$

Table III. Stability of pDERMATT $2 \mathrm{mg} / \mathrm{Vial}$ Lyophilised in $20 \mathrm{mg} / \mathrm{ml}$ Sucrose after Storage at $2-8^{\circ} \mathrm{C}$

\begin{tabular}{cccl}
\hline $\begin{array}{l}\text { Storage time } \\
\text { (months) }\end{array}$ & Content $(\%)$ & SC Purity $(\%)$ & $\begin{array}{l}\text { Residual } \\
\text { moisture }(\%)\end{array}$ \\
\hline 0 & 99.6 & 98.4 & $0.7( \pm 0.07)$ \\
3 & 98.0 & 98.5 & nd \\
6 & 100.8 & 96.2 & $1.96( \pm 0.51)$ \\
9 & 98.7 & 96.9 & nd \\
12 & 98.4 & 96.3 & $2.20( \pm 0.01)$ \\
18 & 96.9 & 97.4 & nd \\
24 & 97.4 & 99.0 & $2.39( \pm 0.09)$ \\
\hline
\end{tabular}

nd not determined 
of the PW formulations are high and will very likely not be reached during shelf life under common pharmaceutical storage conditions. Only when stored at a higher temperature $\left(40^{\circ} \mathrm{C} /\right.$ $75 \% \mathrm{RH}$ ) and moreover in combination with high moisture levels rapid and significant reduction of SC content occurs. The poor storage stability of PW sucrose may be due to crystallisation of the sugar. Sucrose is known to crystallise readily when stored at temperatures above its $\operatorname{Tg}(32,33)$ and crystallisation is associated with moisture desorption (34). In fact, it has been shown that lyophilised sucrose shows moisture sorption followed by desorption when stored at relative humidities ranging from $33-80 \%$ for a prolonged period of time $(34,35)$. Crystalline sucrose is anhydrous, therefore the water content of the remaining amorphous phase increases and its $\mathrm{Tg}$ decreases (19). With a decrease in $\mathrm{Tg}$, the crystallisation temperature also decreases from $125^{\circ} \mathrm{C}$ at $0.8 \%$ residual water to $65^{\circ} \mathrm{C}$ at $8.4 \%$ residual water, as is comparable to data reported by SalekiGerhardt (32). This apparent paradox in Tg temperature and structure preservation has been reported previously $(9,18,36)$. Even though sucrose has the lowest $\mathrm{Tg}$ temperature it does give the lowest aggregation rate (18) or the highest transfection efficiency (9). It is speculated that sucrose might stabilise pDNA by directly interacting with pDNA rather than by vitrifying to a high-Tg solid (9). In lipid/DNA formulations sucrose might isolate individual particles in the unfrozen fraction during lyophilisation, thus preventing aggregation and loss of transfection efficiency (36). Also the fact that sucrose is a nonreducing sugar could explain why sucrose is a better protector during lyophilisation. Since trehalose is also a non-reducing sugar it is expected that trehalose would have similar protective properties to sucrose if this plays a role. It is not clear why during accelerated storage maltose and lactose are not as good in protecting the pDNA structure as sucrose and trehalose, especially when comparing at $40^{\circ} \mathrm{C} / 75 \% \mathrm{RH}$ (Fig. 2). Maltose and lactose are both reducing sugars, which could play a role.

Surprisingly, when tattooing the different formulations into an ex vivo human skin model, the different disaccharides do affect antigen expression of plasmid DNA, probably as a result of the higher viscosity of the disaccharide solutions compared to pure water. Maltose performed better than trehalose and lactose, but no significant difference with sucrose was found. Furthermore, the differences in antigen expression are limited $(2.8 \%$ lower AUC for sucrose than when dissolved in water), and although a higher antigen expression is correlated to a higher immune response (37), we do not expect this to be clinically relevant. In view of this and the performance of the FD formulation at the $25^{\circ} \mathrm{C} / 60 \% \mathrm{RH}$ and $40^{\circ} \mathrm{C} / 75 \% \mathrm{RH}$ conditions, sucrose was selected as lyoprotectant for pDERMATT. To prevent the amorphous lyophilised formulation from undergoing moisture induced crystallisation we selected a long-term storage condition of 2$8^{\circ} \mathrm{C}$, well below its $\mathrm{Tg}$ value of $46^{\circ} \mathrm{C}$ (34). Table III shows that under this storage condition the sucrose-based formulation is stable for at least 24 months. As expected, residual moisture content increased only slightly and no physical collapse of the cake was seen. Currently, stability studies substantiating a long-term storage condition of $15-25^{\circ} \mathrm{C}$ are ongoing using a shelf-life specification of $\geq 80 \%$ SC pDNA. We recently demonstrated that in the range of $100 \%$ to $75 \%$ SC pDNA antigen expression drops linearly, but only with $10 \%$ (38). This is due to the fact that OC pDNA, the main degradation product upon storage, still gives relatively high levels of antigen expression. In line with this, the US Food and Drug Agency (FDA) recommends that the fraction of the SC topoisoform in pDNA vaccines is at least $80 \%$ (www.fda.gov/ cber/gdlns/plasdnavac.htm). In conclusion, we have demonstrated that disaccharides, like sucrose and trehalose, can be used as naked pDNA lyoprotectants.

\section{ACKNOWLEDGEMENTS}

We would like to thank Joost van den Berg of the Department of Pharmacy and Pharmacology (Slotervaart Hospital/The Netherlands Cancer Institute, Amsterdam, The Netherlands) for performing the ex vivo human skin experiments. Andrew Vincent of the Division of Biostatistics (The Netherlands Cancer Institute, Amsterdam, The Netherlands) is acknowledged for performing the statistical analysis.

Open Access This article is distributed under the terms of the Creative Commons Attribution Noncommercial License which permits any noncommercial use, distribution, and reproduction in any medium, provided the original author(s) and source are credited.

\section{REFERENCES}

1. Schleef M, Schmidt T. Animal-free production of ccc-supercoiled plasmids for research and clinical applications. J Gene Med. 2004;6 Suppl 1:S45-53.

2. Przybylowski M, Bartido S, Borquez-Ojeda O, Sadelain M, Riviere I. Production of clinical-grade plasmid DNA for human Phase I clinical trials and large animal clinical studies. Vaccine. 2007;25(27):5013-24.

3. Walther W, Stein U, Voss C, Schmidt T, Schleef M, Schlag PM. Stability analysis for long-term storage of naked DNA: impact on nonviral in vivo gene transfer. Anal Biochem. 2003;318(2):230-5.

4. Anchordoquy TJ, Armstrong TK, Molina MC. Low molecular weight dextrans stabilize nonviral vectors during lyophilization at low osmolalities: concentrating suspensions by rehydration to reduced volumes. J Pharm Sci. 2005;94(6):1226-36.

5. Poxon SW, Hughes JA. The effect of lyophilization on plasmid DNA activity. Pharm Dev Technol. 2000;5(1):115-22.

6. Levy MS, O'Kennedy RD, Ayazi-Shamlou P, Dunnill P. Biochemical engineering approaches to the challenges of producing pure plasmid DNA. Trends Biotechnol. 2000;18(7):296-305.

7. Anchordoquy TJ, Armstrong TK, Molina MC, Allison SD, Zhang Y, Patel MM, et al. Physical stabilization of plasmid DNA-based therapeutics during freezing and drying. In: Costantino HR, Pikal MJ, editors. Lyophilization of biopharmaceuticals. AAPS press; 2004. pp. 605-41.

8. Lee SL, Debenedetti PG, Errington JR, Pethica BA, Moore DJ. A calorimetric and spectroscopic study of DNA at low hydration. J Phys Chem B. 2004;108:3098-106.

9. Maitani Y, Aso Y, Yamada A, Yoshioka S. Effect of sugars on storage stability of lyophilized liposome/DNA complexes with high transfection efficiency. Int J Pharm. 2008;356(1-2):69-75.

10. Molina MC, Armstrong TK, Zhang Y, Patel MM, Lentz YK, Anchordoquy TJ. The stability of lyophilized lipid/DNA complexes during prolonged storage. J Pharm Sci. 2004;93(9):2259-73.

11. Anchordoquy TJ, Koe GS. Physical stability of nonviral plasmidbased therapeutics. J Pharm Sci. 2000;89(3):289-96.

12. Molina MD, Anchordoquy TJ. Formulation strategies to minimize oxidative damage in lyophilized lipid/DNA complexes during storage. J Pharm Sci. 2008;97(12):5089-105.

13. van Winden E. Freeze-drying of liposomes: a critical review of mechanisms involved in lyoprotection and solid-state stability. In: 
Costantino HR, Pikal MJ, editors. Lyophilization of biopharmaceuticals. AAPS press; 2004. pp. 563-604.

14. Szoka F, Wang J. The regents of the University of California, editor. Stabilized polynucleotide complexes and methods. Oakland, CA (US) patent US 7,323,297 BI. 2008.

15. Allison SD, Anchordoquy TJ. Mechanisms of protection of cationic lipid-DNA complexes during lyophilization. J Pharm Sci. 2000;89(5):682-91.

16. Hinrichs WL, Sanders NN, De Smedt SC, Demeester J, Frijlink HW. Inulin is a promising cryo- and lyoprotectant for PEGylated lipoplexes. J Control Release. 2005;103(2):465-79.

17. Ando S, Putnam D, Pack DW, Langer R. PLGA microspheres containing plasmid DNA: preservation of supercoiled DNA via cryopreparation and carbohydrate stabilization. J Pharm Sci. 1999;88(1):126-30.

18. Chang LL, Shepherd D, Sun J, Ouellette D, Grant KL, Tang XC, et al. Mechanism of protein stabilization by sugars during freezedrying and storage: native structure preservation, specific interaction, and/or immobilization in a glassy matrix? J Pharm Sci. 2005;94(7):1427-44.

19. Kreilgaard L, Frokjaer S, Flink JM, Randolph TW, Carpenter JF. Effects of additives on the stability of recombinant human factor XIII during freeze-drying and storage in the dried solid. Arch Biochem Biophys. 1998:360(1):121-34.

20. Kendrick BS, Chang BS, Arakawa T, Peterson B, Randolph TW, Manning MC, et al. Preferential exclusion of sucrose from recombinant interleukin-1 receptor antagonist: role in restricted conformational mobility and compaction of native state. Proc Natl Acad Sci USA. 1997;94(22):11917-22.

21. Sharma VK, Klibanov AM. Moisture-induced aggregation of lyophilized DNA and its prevention. Pharm Res. 2007;24(1):168-75.

22. Shamblin S. The role of water in physical transformations in freeze-dried products. In: Costantino HR, Pikal MJ, editors. Lyophilization of biopharmaceuticals. Arlington, VA: AAPS; 2004. p. 229-70.

23. Quaak SGL, Berg JH, Toebes M, Schumacher T, Beijnen JH, Nuijen B. GMP production of pDERMATT for vaccination against melanoma in a phase I clinical trial. Eur J Pharm Biopharm. 2008;70(2):429-38.

24. Quaak SGL, Nuijen B, Haanen JB, Beijnen JH. Development and validation of an LC-UV method for the quantification and purity determination of pDERMATT. J Pharm Biomed Anal. 2009;49(2):282-8

25. van den Berg JH, Nuijen B, Beijnen JH, Vincent A, Van Tinteren $\mathrm{H}$, Kluge $\mathrm{J}$, et al. Optimization of intradermal vaccination by DNA tattooing in human skin. Hum Gene Ther. 2009;20(3):181-9.
26. Oesterle J, Franks F, Auffret T. The influence of tertiary butyl alcohol and volatile salts on the sublimation of ice from frozen sucrose solutions: implications for freeze-drying. Pharm Dev Technol. 1998;3(2):175-83.

27. Costantino HR. Exipients for use in lyophilized pharmaceutical peptide, protein and other bioproducts. In: Costantino HR, Pikal MJ, editors. Lyophilization of biopharmaceuticals. Arlington, VA: AAPS; 2004. p. 139-228.

28. Van Drooge DJ, Hinrichs WL, Frijlink HW. Incorporation of lipophilic drugs in sugar glasses by lyophilization using a mixture of water and tertiary butyl alcohol as solvent. J Pharm Sci. 2004;93(3):713-25.

29. Tang X, Pikal MJ. Design of freeze-drying processes for pharmaceuticals: practical advice. Pharm Res. 2004;21(2):191200.

30. Jameel F, Amsberry KL, Pikal MJ. Freeze drying properties of some oligonucleotides. Pharm Dev Technol. 2001;6(2):151-7.

31. Kawai K, Suzuki T. Stabilizing effect of four types of disaccharide on the enzymatic activity of freeze-dried lactate dehydrogenase: step by step evaluation from freezing to storage. Pharm Res. 2007;24(10):1883-90.

32. Saleki-Gerhardt A, Zografi G. Non-isothermal and isothermal crystallization of sucrose from the amorphous state. Pharm Res. 1994;11(8):1166-73.

33. Sarciaux JM, Hageman MJ. Effects of bovine somatotropin (rbSt) concentration at different moisture levels on the physical stability of sucrose in freeze-dried $\mathrm{rbSt} /$ sucrose mixtures. J Pharm Sci. 1997;86(3):365-71.

34. Yu X, Kappes SM, Bello-Perez LA, Schmidt SJ. Investigating the moisture sorption behavior of amorphous sucrose using a dynamic humidity generating instrument. J Food Sci. 2008;73 (1):E25-35.

35. Carstensen JT, Van Scoik K. Amorphous-to-crystalline transformation of sucrose. Pharm Res. 1990;7(12):1278-81.

36. Allison SD, Molina MC, Anchordoquy TJ. Stabilization of lipid/ DNA complexes during the freezing step of the lyophilization process: the particle isolation hypothesis. Biochim Biophys Acta. 2000;1468(1-2):127-38.

37. Bins AD, Jorritsma A, Wolkers MC, Hung CF, Wu TC, Schumacher TN, et al. A rapid and potent DNA vaccination strategy defined by in vivo monitoring of antigen expression. Nat Med. 2005;11(8):899-904.

38. Quaak SGL, Berg JH, Beijnen JH, Haanen J, Nuijen B. DNA tattoo vaccination: effect on plasmid purity and transfection efficiency of different topoisoforms. J Control Release. 2009;139 (2):153-9. 